\title{
Effect of the spatial network structure and cross-link density of diene rubbers on their thermal stability and fire hazard
}

\author{
Przemysław Rybiński • Grażyna Janowska
}

Received: 12 August 2013/Accepted: 27 January 2014/Published online: 16 February 2014

(C) The Author(s) 2014. This article is published with open access at Springerlink.com

\begin{abstract}
The paper presents the results of investigating the effect of the density and spatial network structure of diene rubbers (NBR and SBR) on their thermal properties and fire hazard. The rubbers were either conventionally cross-linked by means of sulfur and organic peroxide or nonconventionally with the use of iodoform $\left(\mathrm{CH}_{3} \mathrm{I}\right)$. Based on thermo-kinetic analysis, the destruction activation energy of the elastomers investigated and their vulcanizates was determined under air and inert gas. The analysis of particular stages of their thermal decomposition was also presented. During the combustion of the elastomeric materials obtained, it has been found that their fire hazard depends not only on the elastomer chemical structure but also on the method of its cross-linking.
\end{abstract}

Keywords Butadiene-styrene rubber · Nitrile rubber . Activation energy of destruction · Fire hazard - Structure of 3-dimensional network

\section{Introduction}

As a result of elastomers cross-linking, their macromolecules are combined by means of crosswise chemical bonds forming a spatial network. Elastomers are usually crosslinked by means of sulfur or its donors, organic peroxides, or rarely high-energy radiation. This process results in the

\section{P. Rybiński ( $\square)$}

Management of Environment Protection and Modeling, The Jan

Kochanowski University, Kielce, Poland

e-mail: przemyslaw.rybinski@ujk.edu.pl

G. Janowska

Institute of Polymer and Dye Technology, Technical University

of Łódź, Lodz, Poland formation of conventional spatial networks containing sulfide or carbon-carbon bonds. It is commonly accepted that cross-linking increases the thermal stability of elastomers. Polymers with ladder-like structures or strongly crosslinked duromers show exceptionally high-thermal stability. However, the degradation mechanism of the elastomer spatial networks has various aspects. The conventional cross-linking of elastomers causes that the concentration of network nodes is relatively low; on the average, one network node falls to 100 monomeric units of the main chain. Such a spatial network exerts a great influence on the oscillatory motions and rotation freedom of chain links. It only impedes, and above the gel point totally excludes the translator motions that slightly affect the course and yield of the elastomer degradation. Some types of network nodes, e.g., polysulfide or diurethane nodes contain chemical bonds with a low energy, below $260 \mathrm{~kJ} \mathrm{~mol}^{-1}$. The thermal degradation of elastomer cross-linked in this way can consist in splitting the network nodes. Their thermal dissociation results in the formation of radicals that can initiate consequent processes of main chains degradation. The cross-linkers and accelerants contained in elastomers, even in trace quantities, can also decrease their thermal stability. These easily undergo thermal decomposition, in consequence of which small-molecular radicals are formed showing a high activity and capability to initiate various reactions of macromolecules and network nodes, and first of all, their thermo-oxidative degradation. The assessment of the effect of spatial network structure and cross-linkers on the thermal stability of polymers is particularly difficult.

The present study deals with the effect of the density and spatial network structure on the thermal properties of NBR and SBR rubbers, commonly used in the rubber industry, conventionally cross-linked with sulfur or organic peroxide, and non-conventionally with the use of iodoform. 
A particular attention was devoted to changes in the destruction activation energy of the vulcanizates obtained depending on cross-link density, spatial network structure, and test atmosphere.

\section{Experimental}

\section{Materials}

The objects of studies were butadiene-acrylonitrile rubber (NBR), NBR $2.255 \mathrm{~V}$, containing $22 \%$ of combined acrylonitrile, from Lanxess, and butadiene-styrene rubber (SBR), KER 1500, containing $23.5 \%$ of combined styrene from Synthos. The rubbers were cross-linked by means of dicumyl peroxide (DCP) in the presence of zinc oxide $(\mathrm{ZnO})$ or by means of sulfur in the presence of $\mathrm{ZnO}$ and $\mathrm{N}$ cyclohexyl-2-benzylsulfenamide (Tioheksam CBS).

Obtained peroxide and sulfur vulcanizates of NBR and SBR rubbers have different degrees of cross-linking.

The resultant peroxide vulcanizates of NBR rubber were denoted with $\mathrm{NN}$ (NN1, NN2, and NN3), while the sulfur with NS (NS1, NS2, and NS3). The peroxide vulcanizates of SBR rubber were denoted with SN (SN1, SN2, and SN3), while the sulfur with SS (SS1, SS2, and SS3).

The rubbers were also examined after their non-conventional cross-linking with the use of iodoform, $\mathrm{CH}_{3} \mathrm{I}$. The iodoform vulcanizate of NBR and SBR was denoted with NI and SI, respectively.

\section{Methods}

Elastomeric mixtures were prepared at room temperature with the use of a laboratory rolling mill $(D=150 \mathrm{~mm}$ and $L=300 \mathrm{~mm}$ ). The rotational speed of the front roll was $20 \mathrm{rpm}$, friction 1.1.

The mixtures were vulcanized in steel molds placed between electrically heated press shelves. The optimal vulcanization time $\left(\tau_{0.9}\right)$ at a temperature of $160{ }^{\circ} \mathrm{C}$ was determined by means of a WG-2 vulcameter according to PN-ISO 3417:1994.

\section{Thermal properties}

The thermal properties of the rubbers (SBR and NBR) were tested under air within the temperature range of $25-800{ }^{\circ} \mathrm{C}$ by means of a MOM derivatograph (Budapest), using $\mathrm{Al}_{2} \mathrm{O}_{3}$ as a reference substance. Weighed portions were $90 \mathrm{mg}$ each, heating rate $7.9^{\circ} \mathrm{C} \mathrm{min}-1$, and the sensitivities of thermal curves were as follows: $\mathrm{TG}=100$, $\mathrm{DTA}=1 / 5$, and DTG $=1 / 30$.

The thermal properties of cross-linked mixtures were determined under air and nitrogen atmosphere within the temperature range of $25-700{ }^{\circ} \mathrm{C}$, by means of the thermal analyzer Jupiter STA 449 F3 from Netzsch Company (weighed portions 5-10 $\mathrm{mg}$ and heating rate 2, 5, 10, 15, and $20{ }^{\circ} \mathrm{C} \mathrm{min}^{-1}$ ).

Thermal analysis under nitrogen at -100 to $500{ }^{\circ} \mathrm{C}$ was carried out by the method of differential scanning calorimetry using a DSC-204 micro-calorimeter (Netzsch) and 5-7 $\mathrm{mg}$ weighed portions at a heating rate of $10{ }^{\circ} \mathrm{C} \mathrm{min}^{-1}$.

\section{Determination of activation energy of decomposition investigation vulcanizates}

The activation energy of decomposition of vulcanizates has been calculated by the use of Flynn-Wall-Ozawa method.

The analysis is based on the well-known Flynn-WallOzawa iso-conversional method. This iso-conversional integral method suggested independently by Flynn and Wall and Ozawa uses Doyle's approximation of the temperature integral. This method is based on the equations [1-3]

$\log \beta=\log \frac{A E}{R g(\alpha)}-2.315-\frac{0.457 E}{R T}$

where $\beta$ is the heating rate ${ }^{\circ} \mathrm{C} \min ^{-1}, A$ is the preexponential factor, $E$ is the activation energy of decomposition in $\mathrm{kJ} \mathrm{mol}^{-1}, R$ is the universal gas constant, $\alpha$ is the degree of conversion, and $T$ is the absolute temperature to reach the conversion and is the integral conversion function.

$g(\alpha)=\int_{0}^{\alpha} \frac{\mathrm{d} \alpha}{f(\alpha)}$

Thus, at a constant conversion ( $\alpha=$ const.), the plot log $\beta$ versus $(1 / T)$, obtained from a series experiments performed at several heating rates, should be a straight line slope of which allows evaluation of the activation energy.

slope $=\frac{\mathrm{d}(\log \beta)}{\mathrm{d}(1 / T)}=0.4567\left(\frac{E}{R}\right)$

To apply this iso-conversional method, heating rates of $2,5,10,15$, and $20{ }^{\circ} \mathrm{C} \min ^{-1}$ were chosen. In this study, the conversion values of $10,20,30,40,50,60,70,80$, and $90 \%$ have been used, which would give $\alpha$ values $0.1,0.2$, $0.3,0.4,0.5,0.6,0.7,0.8$, and 0.9 respectively for the Flynn-Wall-Ozawa method.

\section{Determination of cross-link density}

Equilibrium swelling method was used to determine the cross-link density of the vulcanizates. Samples were swollen in the toluene at the temperature $T=25{ }^{\circ} \mathrm{C}$ for $48 \mathrm{~h}$ and then removed from the solvent, and the surface 
toluene was quickly blotted off. The samples were immediately weighed and then dried in a vacuum oven for $36 \mathrm{~h}$ at $80{ }^{\circ} \mathrm{C}$ to remove all the solvent and reweighed.

The value of equilibrium swelling is calculated by the following equation:

$Q_{\mathrm{w}}=\frac{m_{\mathrm{sp}}-m_{\mathrm{s}}}{m_{\mathrm{s}}^{*}}$

where $Q_{\mathrm{w}}$ is the equilibrium swelling, $m_{\mathrm{sp}}$ is the mass of swelling sample/mg, $m_{\mathrm{s}}$ is the mass of dried sample after swelling $/ \mathrm{mg}$, and $m_{\mathrm{s}}^{*}$ is the mass of dried sample after swelling, corrected with the contribution of mineral substances/mg.

$m_{\mathrm{s}}^{*}=m_{\mathrm{s}}-m_{\mathrm{o}}\left(m_{\mathrm{n}} / m_{\mathrm{c}}\right)$

where $m_{\mathrm{o}}$ is the initial mass of sample/mg, $m_{\mathrm{n}}$ is the mass of mineral substances contained in the blend/mg, and $m_{\mathrm{c}}$ is the mass of all blend components/mg.

The degree of cross-linking $\alpha_{C}$ was calculated by the following equation:

$\alpha_{\mathrm{C}}=\frac{1}{Q_{\mathrm{w}}}$

The result of equilibrium swelling was an arithmetical average of four determinations.

Equilibrium volumetric swelling $Q_{\mathrm{v}}$, determined from the equation

$Q_{\mathrm{v}}=Q_{\mathrm{w}} \times\left(\frac{d_{\mathrm{k}}}{d_{\mathrm{r}}}\right)$

where $d_{\mathrm{k}}$ is the rubber density in vulcanizate $/ \mathrm{gcm}^{-3}$ and $d_{\mathrm{r}}$ is the solvent density. Density of toluene is $0.866 / \mathrm{gcm}^{-3}$.

The elastically active network chain $v$, which was used to represent the whole cross-link density, was then calculated by the well-known Flory-Rehner equation $[4,5]$.

$V_{\mathrm{r}}=1 /\left(1+Q_{\mathrm{v}}\right)$

$v=-\frac{\ln \left(1-V_{\mathrm{r}}\right)+V_{\mathrm{r}}+\mu V_{\mathrm{r}}^{2}}{V_{0}\left(V_{\mathrm{r}}^{\frac{1}{3}}-\frac{2 V_{\mathrm{r}}}{f}\right)}$

where $v$ is the concentration of effective chains [mol cm $\left.\mathrm{cm}^{-3}\right], V_{\mathrm{r}}$ is the volume fraction of the polymer in the vulcanizate swollen to equilibrium, $V_{0}$ is the solvent molar volume (for toluene $V_{\mathrm{s}}=107 \mathrm{~cm}^{3} \mathrm{~mol}^{-1}$ ), $f$ is the functionality of network, and $\mu$ is the Huggins parameter of the interactions between cross-linked rubber and solvent being a linear function of cross-link density $V_{\mathrm{r}}$.

\section{Flammability}

Flammability of vulcanizates was examined by the FAA micro-calorimeter from the Fire Testing Technology Limited, with a constant flow ratio of oxygen to nitrogen being $1: 4$. The temperature of pyrolyzer was $750{ }^{\circ} \mathrm{C}$, while
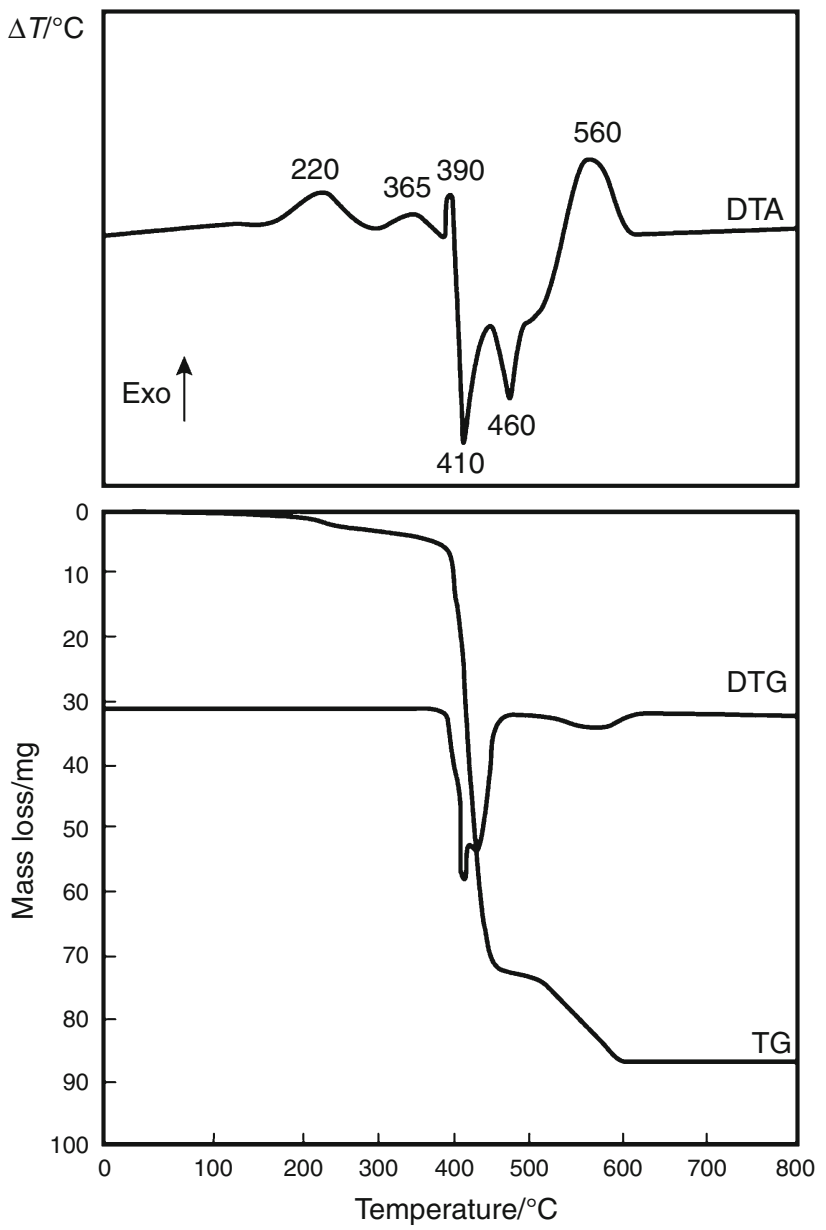

Fig. 1 Thermal curves of NBR rubber in air atmosphere

that of combustor $900{ }^{\circ} \mathrm{C}$. During measurement, the following parameters were recorded: ignition temperature, maximal heat emission rate, temperature of maximal heat emission rate, total heat emitted, and heat capacity [6-8].

Results and discussion

NBR and SBR rubbers in the atmosphere of air undergo two-stage thermal cross-linking as indicated by signals of the first ( $T_{\mathrm{I}} 220$ and $230{ }^{\circ} \mathrm{C}$, respectively) and second ( $T_{\mathrm{II}}$ 365 and $380{ }^{\circ} \mathrm{C}$, respectively) exothermic transition recorded in DTA curves (Figs. 1, 2).

The first stage of thermal cross-linking under air occurs as a result of the decomposition of hydroperoxide groups contained in the elastomer and formed due to its heating. The second stage is caused by the thermal polymerization of butadiene monomeric units.

The volumetrically great phenyl substituent in SBR macromolecules, causing their stiffening, increases the temperature of both the first and second exothermic process in relation to NBR rubber, also increasing the contribution 

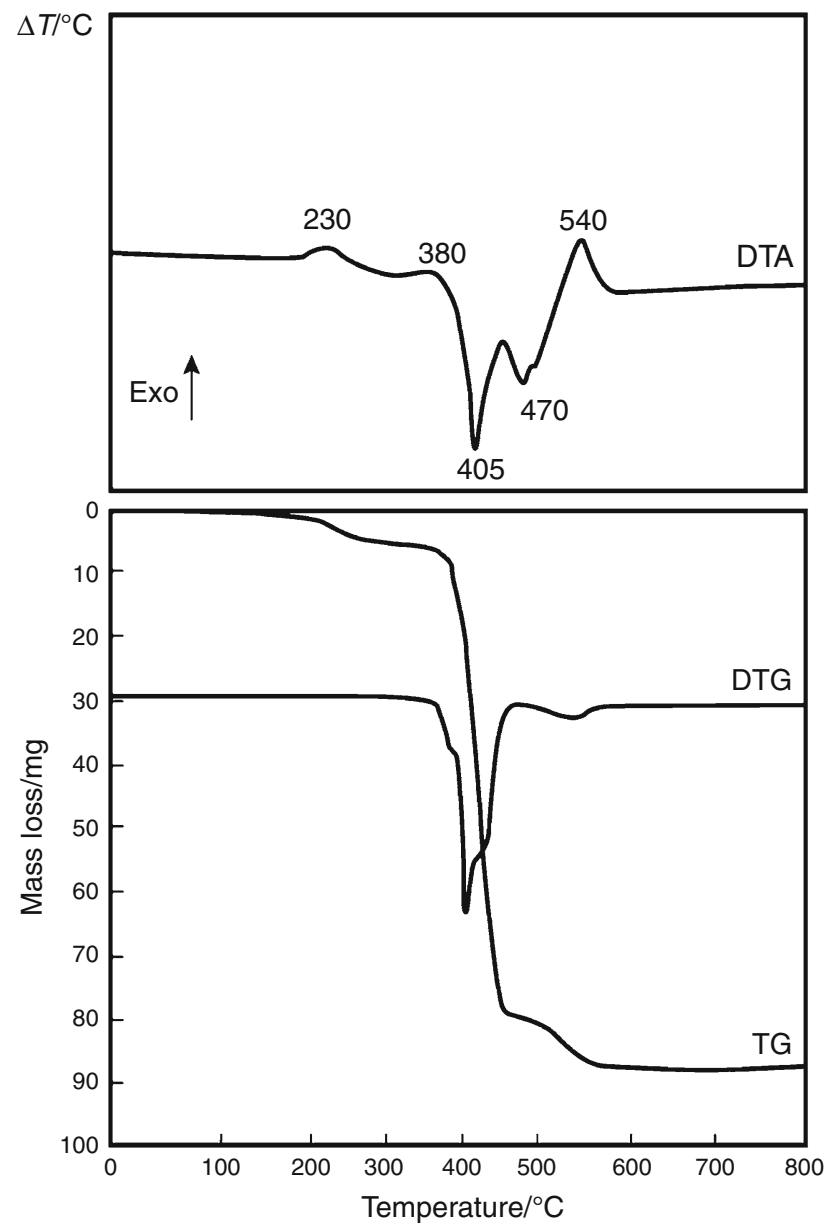

Fig. 2 Thermal curves of SBR rubber in air atmosphere

of chain fragmentation as indicated by the values of parameters $T_{5}, T_{50}$, and $T_{\mathrm{R}}$ (Figs. 1, 2; Table 1). These substituents, in consequence of mesomeric, steric and first of all induction effects, decrease the energy of valence bonds in the main elastomer chain. In typical carbon-chain elastomers, the value of a single $\mathrm{C}-\mathrm{C}$ bond amounts to

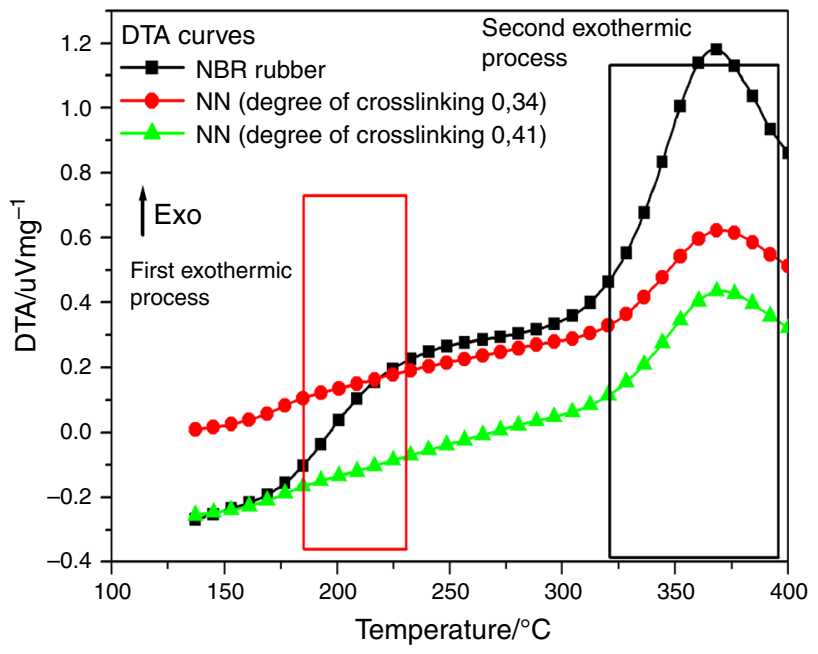

Fig. 3 DTA curves in air atmosphere of NBR rubber before and after its cross-linking

$244 \mathrm{~kJ} \mathrm{~mol}^{-1}$ in butadiene-styrene copolymers, and to $324 \mathrm{~kJ} \mathrm{~mol}^{-1}$ in butadiene-acrylonitrile copolymers $[9,10]$.

The maximal decomposition rate of the elastomers under investigation occurs at $T \approx 400{ }^{\circ} \mathrm{C}$, while the combustion of the thermal decomposition residue at $\Delta T=520-600{ }^{\circ} \mathrm{C}$ and $\Delta T=485-560{ }^{\circ} \mathrm{C}$ for NBR and SBR rubbers, respectively.

The presence of polar substituent in NBR causes a considerable increase in the value of cohesion energy, approximately by $100 \mathrm{MJm}^{-3}$, between its chains in relations to SBR. It results in both considerable increase in the NBR thermal decomposition residue, $P w$, and a lower rate of its thermal decomposition, $\mathrm{d} m / \mathrm{d} t$, in comparison with SBR (Table 1).

The cross-linking of the rubber investigated does not change the character of their thermal conversion. But with increasing their cross-link density the thermal effect,

Table 1 The TG/DTG analysis rubbers before and after their cross-linking

\begin{tabular}{|c|c|c|c|c|c|c|c|c|}
\hline Sample & $T_{5} /{ }^{\circ} \mathrm{C}$ & $T_{50} /{ }^{\circ} \mathrm{C}$ & $T_{\mathrm{R}} /{ }^{\circ} \mathrm{C}$ & $T_{\text {RMAX }} /{ }^{\circ} \mathrm{C}$ & $\mathrm{d} m / \mathrm{d} t / \% \min ^{-1}$ & $P w / \%$ & $T s /{ }^{\circ} \mathrm{C}$ & $P_{700} / \%$ \\
\hline NBR & 350 & 415 & 380 & 390 & 19.5 & 20.8 & 560 & 2 \\
\hline $\mathrm{NN}\left(\alpha_{\mathrm{C}}=0.26\right)$ & 350 & 420 & 390 & 410 & 17.6 & 23.0 & 545 & 9 \\
\hline $\mathrm{NS}\left(\alpha_{\mathrm{C}}=0.21\right)$ & 315 & 405 & 370 & 395 & 17.3 & 23.0 & 540 & 7 \\
\hline $\mathrm{NI}\left(\alpha_{\mathrm{C}}=0.25\right)$ & 290 & 430 & 370 & 430 & 9.8 & 26.9 & 590 & 2 \\
\hline SBR & 270 & 410 & 360 & 405 & 21.1 & 15.8 & 505 & 5 \\
\hline $\mathrm{SN}\left(\alpha_{\mathrm{C}}=0.15\right)$ & 305 & 419 & 365 & 415 & 20.6 & 19.0 & 475 & 5 \\
\hline $\operatorname{SS}\left(\alpha_{C}=0.15\right)$ & 300 & 400 & 350 & 365 & 20.3 & 20.9 & 498 & 8.8 \\
\hline SI $\left(\alpha_{C}=0.22\right)$ & 260 & 420 & 310 & 430 & 10.7 & 27.6 & 610 & 5 \\
\hline
\end{tabular}

$T_{5}$ and $T_{50}$ temperatures of sample 5 and $50 \%$ mass loss, respectively; $T_{\mathrm{R}}$ temperature of thermal decomposition; $T_{\mathrm{RMAx}}$ temperature of maximum rate of thermal decomposition of vulcanizates; $d \mathrm{~m} / d \mathrm{t}$ maximum rate of thermal decomposition of vulcanizates; $P w$ residue after the thermal decomposition of vulcanizates; $T s$ temperature of residue burning after the thermal decomposition of vulcanizates; $P_{700}$ residue after heating up to $T=700{ }^{\circ} \mathrm{C} ; \alpha_{\mathrm{C}}$ degree of cross-linking 


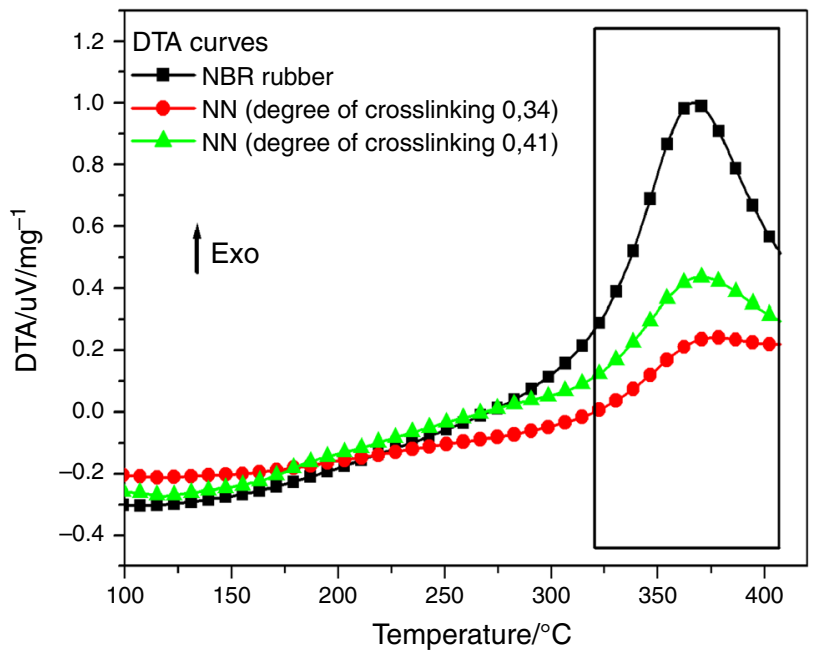

Fig. 4 DTA curves in nitrogen atmosphere of NBR rubber before and after its cross-linking

recorded in DTA curves, both under air and inert gas, accompanying the thermal cross-linking processes, which indicates a lower yield of these chemical reactions (Figs. 3, 4).

From the data listed in Table 1, it follows that independent of the chemical structure of rubber macromolecules, their thermal stability depends on the method of their cross-linking. The higher thermal stability, determined with parameters $T_{5}, T_{50}$, and $T_{\mathrm{RMAX}}$, of the elastomers cross-linked with organic peroxide results from the greater energy of $\mathrm{C}-\mathrm{C}$ bonds in comparison with sulfide bonds. The thermal decomposition rate, $\mathrm{d} m / \mathrm{d} t$, is a very important parameter of the thermal stability of polymers and polymeric materials [11-13]. The analysis of data listed in Table 1 leads to conclusion that the thermal decomposition rate of rubbers cross-linked with organic peroxide is higher than that of rubbers cross-linked with sulfur.

NBR rubber, both before and after its cross-linking is characterized by a lower value of thermal decomposition rate, $\mathrm{d} m / \mathrm{d} t$, in comparison with that of SBR rubber. This follows from its previously mentioned high-cohesion energy, and consequently from its considerably increased tendency to carbonization processes (parameter $P w$, Table 1).

Iodoform vulcanizates (NI and SI) are characterized by the lowest thermal stability determined with parameters $T_{5}$ and $T_{\mathrm{R}}$ in relation to rubbers cross-linked with sulfur or organic peroxide. However, it should be underlined that vulcanizates NI and SI are also characterized by the lowest rate of thermo-oxidative decomposition, and in the case of SBR, also by the greatest residue after this process (vulcanizate SI, Table 1). The cross-linking of NBR and SBR rubbers, regardless of the cross-linker system, clearly
Table 2 The values of energy activation destruction of NBR and SBR rubbers and their vulcanizates

\begin{tabular}{|c|c|c|c|c|}
\hline Sample & $\begin{array}{l}\text { Degree } \\
\text { of cross- } \\
\text { linking } \\
\alpha_{C}\end{array}$ & $\begin{array}{l}\text { cross-link } \\
\text { density, v/ } \\
\text { mol cm }^{-3}\end{array}$ & $\begin{array}{l}\text { Activation } \\
\text { energy } E_{\mathrm{a}} / \\
\mathrm{kJ} \mathrm{mol}^{-1} \text { (air) }\end{array}$ & $\begin{array}{l}\text { Activation } \\
\text { energy } E_{\mathrm{a}} / \\
\mathrm{kJ} \mathrm{mol}^{-1} \\
\text { (nitrogen) }\end{array}$ \\
\hline NBR & - & - & $193.4[10]$ & $217.1 \pm 9.97$ \\
\hline NN1 & 0.27 & $3.30 \times 10^{-5}$ & $239.4 \pm 1.97$ & $210.8 \pm 1.38$ \\
\hline NN2 & 0.34 & $8.73 \times 10^{-5}$ & $257.7 \pm 3.99$ & $221.6 \pm 3.27$ \\
\hline NN3 & 0.41 & $1.10 \times 10^{-4}$ & $281.3 \pm 3.46$ & $242.1 \pm 7.87$ \\
\hline NS1 & 0.08 & $3.13 \times 10^{-5}$ & $213.9 \pm 13.05$ & $205.9 \pm 13.15$ \\
\hline NS2 & 0.22 & $4.35 \times 10^{-5}$ & $234.5 \pm 4.53$ & $224.7 \pm 5.15$ \\
\hline NS3 & 0.46 & $1.02 \times 10^{-4}$ & $259.9 \pm 2.21$ & $235.1 \pm 2.12$ \\
\hline NI & 0.25 & $9.13 \times 10^{-5}$ & $200.1 \pm 5.15$ & $199.7 \pm 3.95$ \\
\hline SBR & - & - & $169[25]$ & $202.4 \pm 16.7^{\mathrm{a}}$ \\
\hline SN1 & 0.16 & $6.15 \times 10^{-5}$ & $247.1 \pm 4.47$ & $220.8 \pm 4.60$ \\
\hline SN2 & 0.27 & $1.16 \times 10^{-4}$ & $250.9 \pm 4.47$ & $230.5 \pm 4.31$ \\
\hline SN3 & 0.31 & $2.07 \times 10^{-4}$ & $258.4 \pm 6.35$ & $234.7 \pm .47$ \\
\hline SS1 & 0.05 & $0.07 \times 10^{-5}$ & $217.7 \pm 10.08$ & $206.6 \pm 13.1$ \\
\hline SS2 & 0.16 & $5.29 \times 10^{-5}$ & $247.8 \pm 6.12$ & $216.1 \pm 4.31$ \\
\hline SS3 & 0.25 & $1.26 \times 10^{-4}$ & $258.7 \pm 5.47$ & $221.6 \pm 3.29$ \\
\hline SI & 0.23 & $1.04 \times 10^{-4}$ & $204.9 \pm 5.04$ & $203.9 \pm 3.43$ \\
\hline
\end{tabular}

${ }^{a}$ The value is in accordance with the data which has been printed in the article [25]

increases their thermal stability expressed with the activation energy of destruction, $E_{\mathrm{a}}$. It indicates an increase in the cage effect in the mechanism of macroradical stabilization, which is clearly visible in the case of chemical processes proceeding under air (Table 2).

The analysis of results listed in Table 2 indicates that both NBR and SBR cross-linked with organic peroxide are characterized by higher values of $E_{\mathrm{a}}$ in comparison with those of the sulfur vulcanizates of these elastomers. The cross-linking by means of DCP results in the formation of crosswise $\mathrm{C}-\mathrm{C}$ bonds with an energy of $268-336 \mathrm{~kJ} \mathrm{~mol}^{-1}$. On the other hand, the use of sulfur cross-linker causes the formation of sulfide network nodes, whose energy amounts to $139-256 \mathrm{~kJ} \mathrm{~mol}^{-1}$. The difference in thermal stability determined with parameter $E_{\mathrm{a}}$ is then a symptom of lower energy of sulfide nodes.

In the case of most polymers, including elastomers, the value of the destruction activation energy under air is lower than that under inert gas since oxygen facilitates the thermo-oxidative processes that are the cause of breaking chemical bonds in macromolecular chains [14].

The investigation results listed in Table 2 show that in the case of cross-linked elastomers, the value of parameter $E_{\mathrm{a}}$ is higher under air than that under nitrogen. From the recent literature reports, it follows that the degradation and thermal destruction processes of elastomers easily undergoing thermal cross-linking according to the thermal 
Table 3 The values of parameter $E_{\mathrm{a}}$ versus parameter alfa for NN vulcanizate

NN vulcanizate $\left(\alpha_{\mathrm{C}}=0.34\right)$

\begin{tabular}{|c|c|c|c|c|c|c|}
\hline \multirow[t]{2}{*}{ Conversion } & \multicolumn{3}{|c|}{ Nitrogen atmosphere } & \multicolumn{3}{|c|}{ Oxygen atmosphere } \\
\hline & $\overline{R^{2}}$ & $E_{\mathrm{a}}$ & & $\overline{R^{2}}$ & $E_{\mathrm{a}}$ & \\
\hline$\alpha 0.1$ & 0.9960 & 236.9 & \pm 3.15 & 0.9281 & 385.2 & \pm 3.43 \\
\hline$\alpha 0.2$ & 0.9957 & 232.9 & \pm 3.23 & 0.9542 & 311.8 & \pm 3.21 \\
\hline$\alpha 0.3$ & 0.9957 & 227.9 & \pm 3.28 & 0.9991 & 299.5 & \pm 3.24 \\
\hline$\alpha 0.4$ & 0.9992 & 222.4 & \pm 3.32 & 0.9994 & 255.7 & \pm 3.27 \\
\hline$\alpha 0.5$ & 0.9992 & 225.8 & \pm 3.35 & 0.9998 & 248.1 & \pm 3.30 \\
\hline$\alpha 0.6$ & 0.9964 & 224.8 & \pm 3.39 & 0.9999 & 221.9 & \pm 3.1 \\
\hline$\alpha 0.7$ & 0.9999 & 220.6 & \pm 3.10 & 0.9999 & 217.1 & \pm 3.1 \\
\hline$\alpha 0.8$ & 0.9956 & 202.3 & \pm 3.15 & 0.9956 & 206.3 & \pm 3.40 \\
\hline$\alpha 0.9$ & 0.9956 & 201.0 & \pm 3.49 & 0.9949 & 173.8 & \pm 3.48 \\
\hline
\end{tabular}

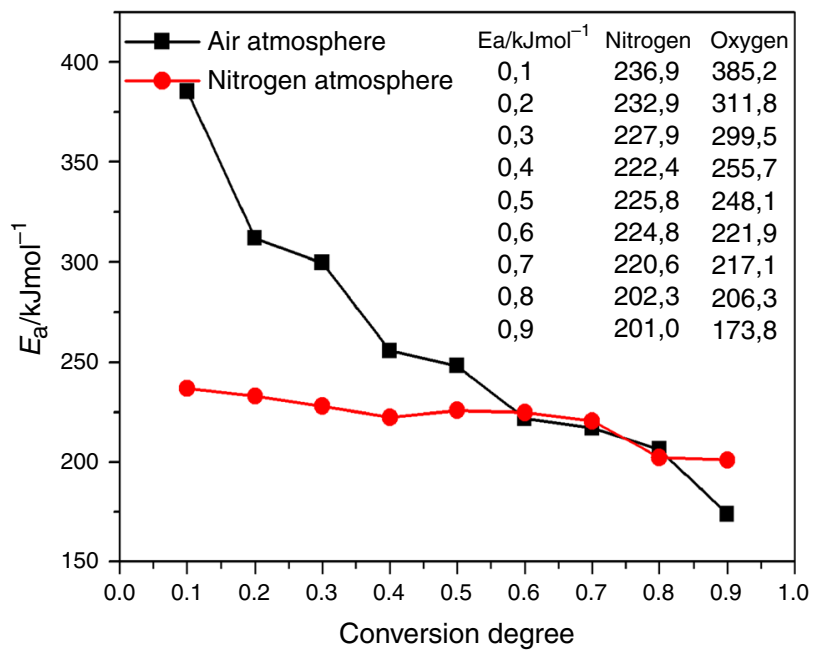

Fig. 5 Relation of value $E_{\mathrm{a}}$ parameter of $\mathrm{NN}$ vulcanizate $\left(\alpha_{\mathrm{C}}=0.34\right)$ from the degree of its thermal decomposition

polymerization mechanism of butadiene monomeric units are unusually complicated [15-17].

In the first stage of the thermal decomposition of crosslinked diene rubbers, characterized by conversion degree $\alpha$, within the range $0.1<\alpha<0.3$, one can observe a homolytic dissociation of bonds, especially in the macromolecule skeleton. Under air, the macroradical formed react with oxygen to form transient peroxide groups that initiate the thermo-oxidative cross-linking of elastomer. The destruction activation energy of NBR cross-linked with DCP under air (cross-linking degree $\alpha_{C}=0.34$ ), for conversion degree $\alpha$ within the range $0.1<\alpha<0.3$ amounts to $\alpha 0.1=385 \mathrm{~kJ} \mathrm{~mol}^{-1}, \quad \alpha 0.2=311 \mathrm{~kJ} \mathrm{~mol}^{-1}, \quad$ and $\alpha 0.3=299 \mathrm{~kJ} \mathrm{~mol}^{-1}$, respectively. Under nitrogen, the values of parameter $E_{\mathrm{a}}$ amount to $\alpha 0.1=236 \mathrm{~kJ} \mathrm{~mol}^{-1}$,
Table 4 The values of parameter $E_{\mathrm{a}}$ versus parameter alfa for SS vulcanizate

\begin{tabular}{|c|c|c|c|c|c|c|}
\hline \multicolumn{7}{|c|}{ Sample SS vulcanizate $\left(\alpha_{C}=0.25\right)$} \\
\hline \multirow[t]{2}{*}{ Conversion } & \multicolumn{3}{|c|}{ Nitrogen atmosphere } & \multicolumn{3}{|c|}{ Oxygen atmosphere } \\
\hline & $R^{2}$ & $E_{\mathrm{a}}$ & & $R^{2}$ & $E_{\mathrm{a}}$ & \\
\hline$\alpha 0.1$ & 0.9990 & 236.6 & \pm 5.14 & 0.9960 & 378.8 & \pm 3.17 \\
\hline$\alpha 0.2$ & 0.9945 & 222.9 & \pm 5.30 & 0.9940 & 346.3 & \pm 3.50 \\
\hline$\alpha 0.3$ & 0.9956 & 229.9 & \pm 5.39 & 0.9987 & 303.0 & \pm 3.20 \\
\hline$\alpha 0.4$ & 0.9997 & 224.4 & \pm 5.45 & 0.9987 & 268.2 & \pm 3.23 \\
\hline$\alpha 0.5$ & 0.9999 & 228.8 & \pm 5.50 & 0.9984 & 222.7 & \pm 3.25 \\
\hline$\alpha 0.6$ & 0.9940 & 221.8 & \pm 5.56 & 0.9969 & 211.6 & \pm 3.29 \\
\hline$\alpha 0.7$ & 0.9983 & 225.6 & \pm 5.61 & 0.9936 & 204.6 & \pm 3.31 \\
\hline$\alpha 0.8$ & 0.9946 & 209.3 & \pm 5.65 & 0.9903 & 195.4 & \pm 3.35 \\
\hline$\alpha 0.9$ & 0.9903 & 210.0 & \pm 5.70 & 0.9801 & 198.3 & \pm 3.37 \\
\hline
\end{tabular}

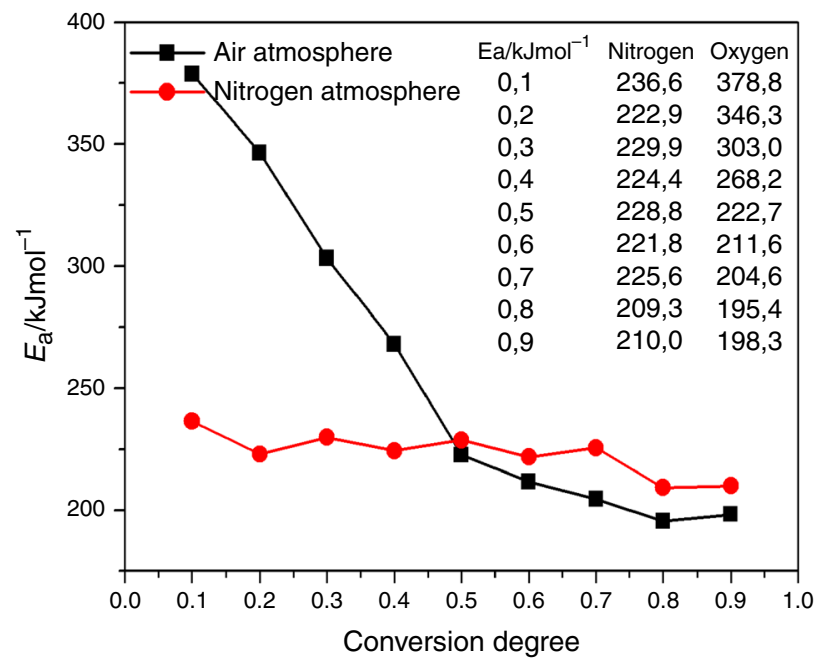

Fig. 6 Relation of value $E_{\mathrm{a}}$ parameter of SS vulcanizate $\left(\alpha_{\mathrm{C}}=0.25\right)$ from the degree of its thermal decomposition

$\alpha 0.2=232 \mathrm{~kJ} \mathrm{~mol}^{-1}$, and $\alpha 0.3=227 \mathrm{~kJ} \mathrm{~mol}^{-1}$, respectively (Tables 2, 3; Fig. 5).

The second stage of thermal decomposition with conversion degree $\alpha$ within the range $0.4<\alpha<0.9$ is connected with the degradation and thermal decomposition of macromolecular chain fragments containing cross-linked and cyclized butadiene monomeric units, which is accompanied by the evolution of small-molecular destruction products such as $\mathrm{CO}, \mathrm{CO}_{2}$, or $\mathrm{HCN}$ [18]. The destruction activation energy, for conversion degree $\alpha$ within the range $0.6<\alpha<0.9$, of both NBR and SBR under air is lower than that under nitrogen (Tables 2, 3, 4; Figs. 5, 6, 7, 8, 9, 10).

Under air as well as under nitrogen, the values of parameter $E_{\mathrm{a}}$ within the range $0.1<\alpha<0.3$ are 


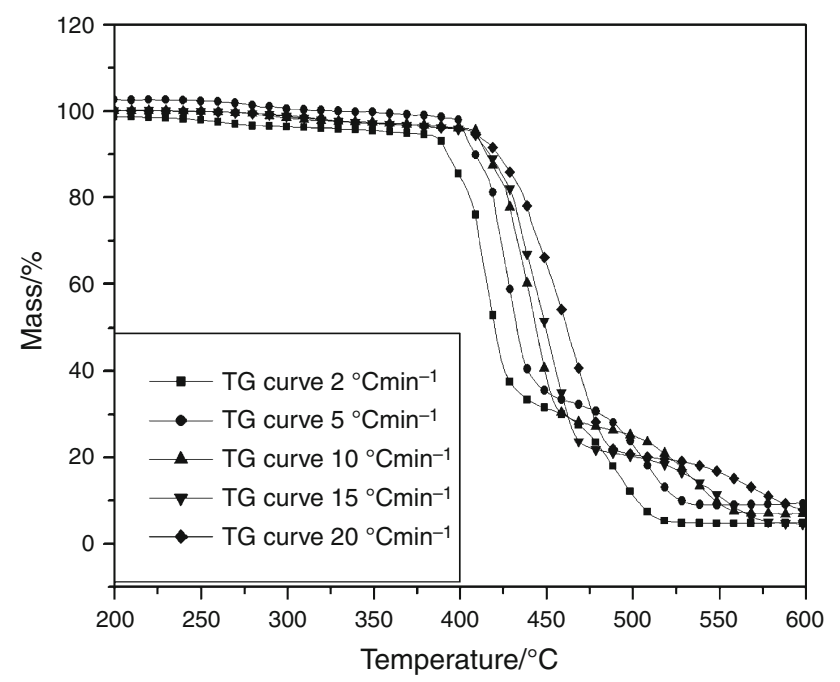

Fig. 7 Thermal curves in air atmosphere of SS vulcanizate $\left(\alpha_{\mathrm{C}}=0.25\right)$

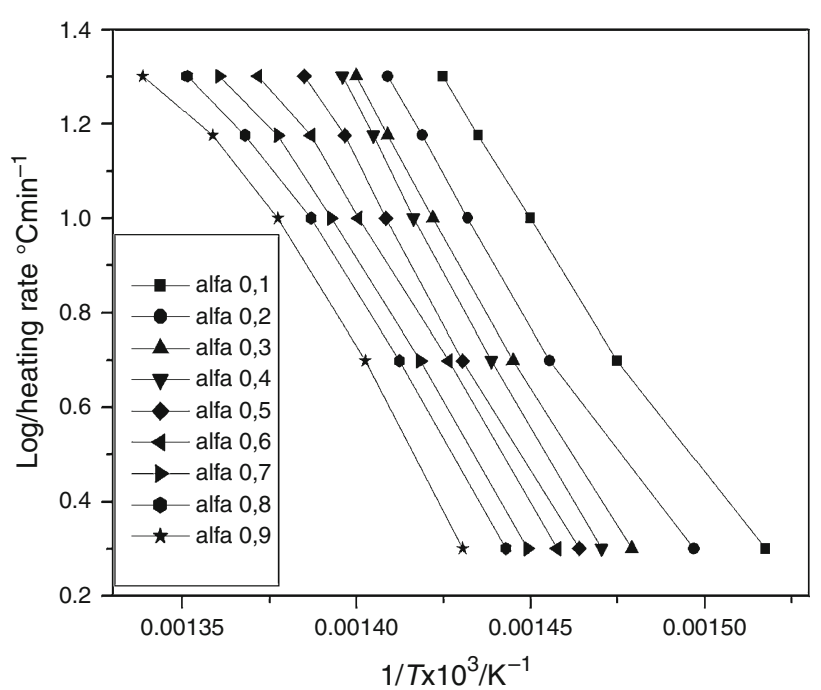

Fig. 8 F-W-O graph of SS vulcanizate $\left(\alpha_{C}=0.25\right)$ in air atmosphere

considerably higher for uncross-linked rubber than those for cross-linked ones [18].

The increase in the destruction activation energy of uncross-linked rubbers in the initial stage of their thermal decomposition in relations to that of cross-linked rubber results first of all from the decomposition of double bonds (the dissociation energy of the carbon-carbon double bond amounts to $580-610 \mathrm{~kJ} \mathrm{~mol}^{-1}$, so it is twice as high as the energy of a single $\mathrm{C}-\mathrm{C}$ bond). The processes of thermooxidative cross-linking within the range of the first and second exothermic transition occur therefore unusually effectively. On the other hand, the values of parameter $E_{\mathrm{a}}$

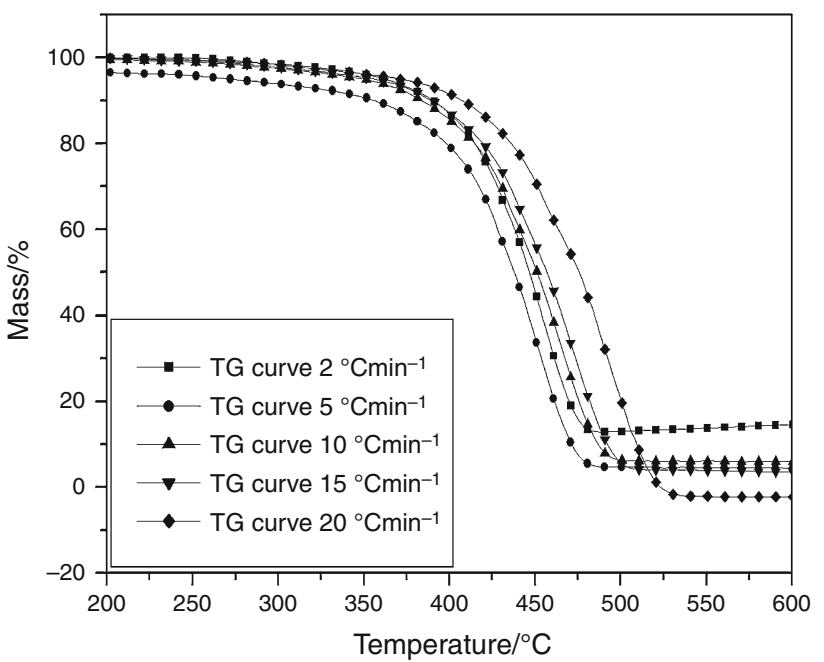

Fig. 9 Thermal curves in nitrogen atmosphere of SS vulcanizate $\left(\alpha_{\mathrm{C}}=0.25\right)$

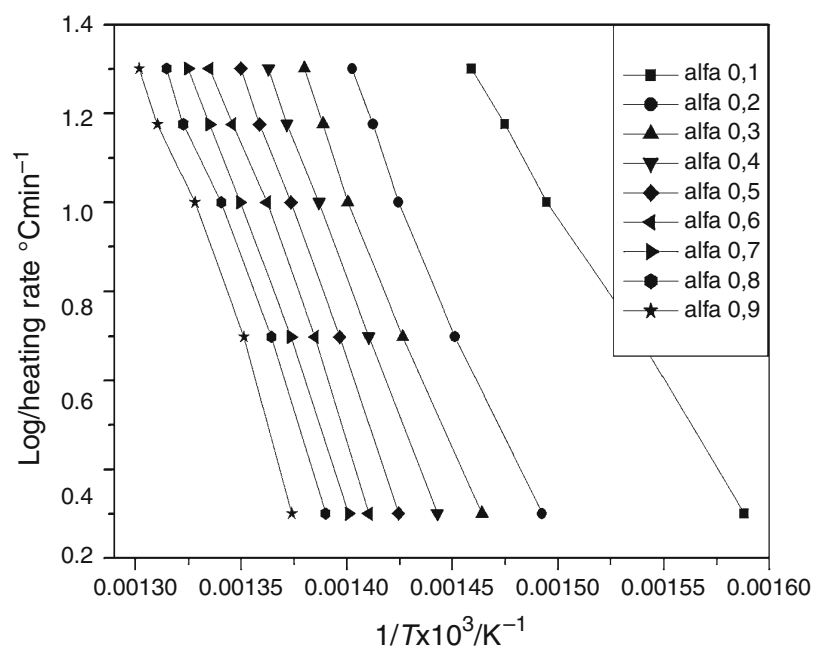

Fig. $10 \mathrm{~F}-\mathrm{W}-\mathrm{O}$ graph of SS vulcanizate $\left(\alpha_{\mathrm{C}}=0.25\right)$ in nitrogen atmosphere

connected with the thermal decomposition of the residue after the first stage of thermal decomposition of uncrosslinked rubbers assume considerably lower values than those of cross-linked elastomers, which indicates a lower degree of the cross-linking and cyclization of the residue after the first stage of thermal decomposition than that of cross-linked rubbers [19, 20].

In the scientific literature, one can find only few reports concerning the thermal properties of elastomers nonconventional cross-linked by means of one of the oldest antiseptics: iodoform [21-23]. The mechanism of cross-linking with this compound can be both ionic and radical, and as in the case of DCP, it leads to the formation of $\mathrm{C}-\mathrm{C}$ network 
Table 5 The DSC results (in nitrogen atmosphere) of vulcanizates of NBR and SBR rubbers

\begin{tabular}{|c|c|c|c|c|c|c|c|}
\hline \multirow[b]{2}{*}{ Sample } & \multicolumn{2}{|c|}{ Cooling } & \multicolumn{5}{|c|}{ Heating } \\
\hline & $T_{\mathrm{g}} /{ }^{\circ} \mathrm{C}$ & $\Delta T_{\mathrm{g}} /{ }^{\circ} \mathrm{C}$ & $T_{\mathrm{g}} /{ }^{\circ} \mathrm{C}$ & $\Delta T_{\mathrm{g}} /{ }^{\circ} \mathrm{C}$ & $\Delta T_{\mathrm{c}} /{ }^{\circ} \mathrm{C}$ & $\Delta H_{\mathrm{c}} / \mathrm{Jg}^{-1}$ & $T_{\mathrm{D}} /{ }^{\circ} \mathrm{C}$ \\
\hline NBR & -53 & -60 to -47 & -43 & -48 to -38 & 279 to 425 & 683 & 457 \\
\hline $\mathrm{NN}\left(\alpha_{\mathrm{C}}=0.26\right)$ & -50 & -80 to -40 & -45 & -66 to -26 & 274 to 426 & 630 & 469 \\
\hline $\mathrm{NS}\left(\alpha_{\mathrm{C}}=0.21\right)$ & -46 & -86 to -36 & -42 & -22 to -62 & 268 to 420 & 650 & 462 \\
\hline $\mathrm{NI}\left(\alpha_{\mathrm{C}}=0.25\right)$ & -47 & -58 to -37 & -41 & -45 to -38 & 187 to 397 & 665 & 460 \\
\hline SBR & -59 & -38 to -68 & -52 & -63 to -23 & 259 to 428 & 593 & 459 \\
\hline $\mathrm{SN}\left(\alpha_{\mathrm{C}}=0.15\right)$ & -60 & -53 to -66 & -52 & -58 to -48 & 261 to 428 & 572 & 462 \\
\hline $\operatorname{SS}\left(\alpha_{C}=0.15\right)$ & -45 & -36 to -54 & -41 & -44 to -38 & 240 to 420 & 479 & 456 \\
\hline SI $\left(\alpha_{C}=0.22\right)$ & -36 & -45 to -26 & -32 & -41 to -24 & 186 to 387 & 704 & 463 \\
\hline
\end{tabular}

$\Delta T_{\mathrm{g}}$ temperature range of glass transition, $\Delta T_{\mathrm{c}}$ temperature of thermal cross-linking, $\Delta H_{\mathrm{c}}$ change of thermal cross-linking enthalpy, $T_{\mathrm{D}}$ temperature of destruction

nodes, which is accompanied by the cis-trans isomerization and modification of rubber macromolecules with iodoform or the products of its decomposition, as confirmed by the similar values of the destruction activation energy of NI and SI vulcanizates under air and nitrogen (Table 2).

The results of thermal analysis obtained under nitrogen indicate that the cross-linking of the rubbers investigated by means of organic peroxide slightly influences their glass-transition temperature $T_{\mathrm{g}}$, during both cooling and heating. On the other hand, there are clear differences between the glass-transition temperatures of rubbers crosslinked with organic peroxide and sulfur (Table 5).

From the data listed in Table 5, it follows that the clear increase in $T_{\mathrm{g}}$ values, determined on the basis of both cooling and heating curves, is recorded for the rubber with a nonpolar structure, i.e., SBR cross-linked with iodoform

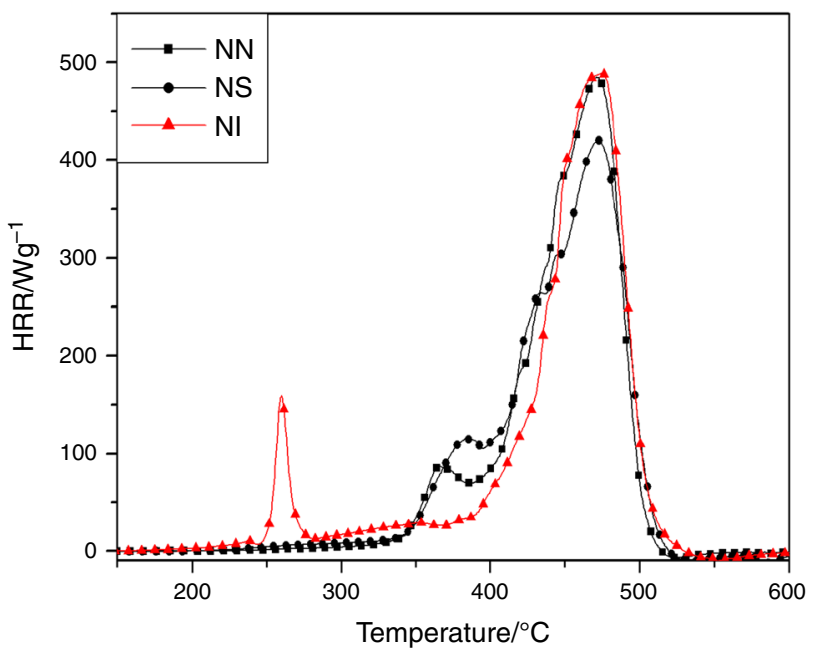

Fig. 11 HRR curves of NBR vulcanizates in comparison with the $T_{\mathrm{g}}$ value of that rubber cross-linked with organic peroxide or sulfur.

Regardless of the cross-linker system used, the crosslinking of the rubbers under investigation decisively decreases their susceptibility to thermal cross-linking as confirmed by the value of parameter $\Delta H_{\mathrm{c}}$ (Table 5). Based on parameter $\mathrm{HRR}_{\mathrm{MAX}}$ determining the maximal rate of heat release during the combustion of the elastomeric materials obtained, it may be concluded that the fire hazards of peroxide and iodoform vulcanizates of SBR are comparable, while the fire hazard of the iodoform vulcanizate of SBR is considerably lower than that of its peroxide vulcanizate (Figs. 11, 12).

From the comparative analysis of Figs. 11 and 12, it follows that the temperature at which heat is released during the combustion of the elastomer obtained is $T \approx 350{ }^{\circ} \mathrm{C}$. In the case of iodoform vulcanizates,

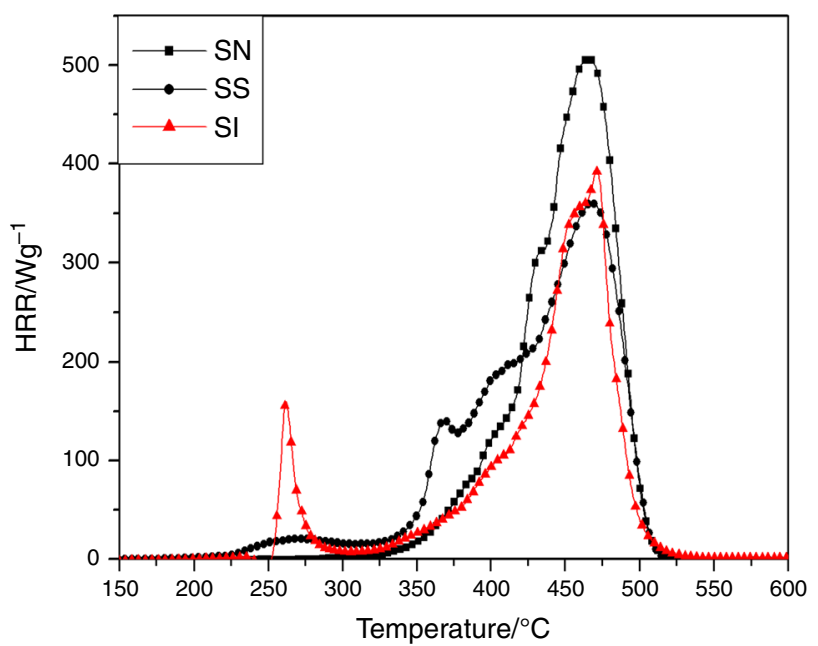

Fig. 12 HRR curves of SBR vulcanizates 

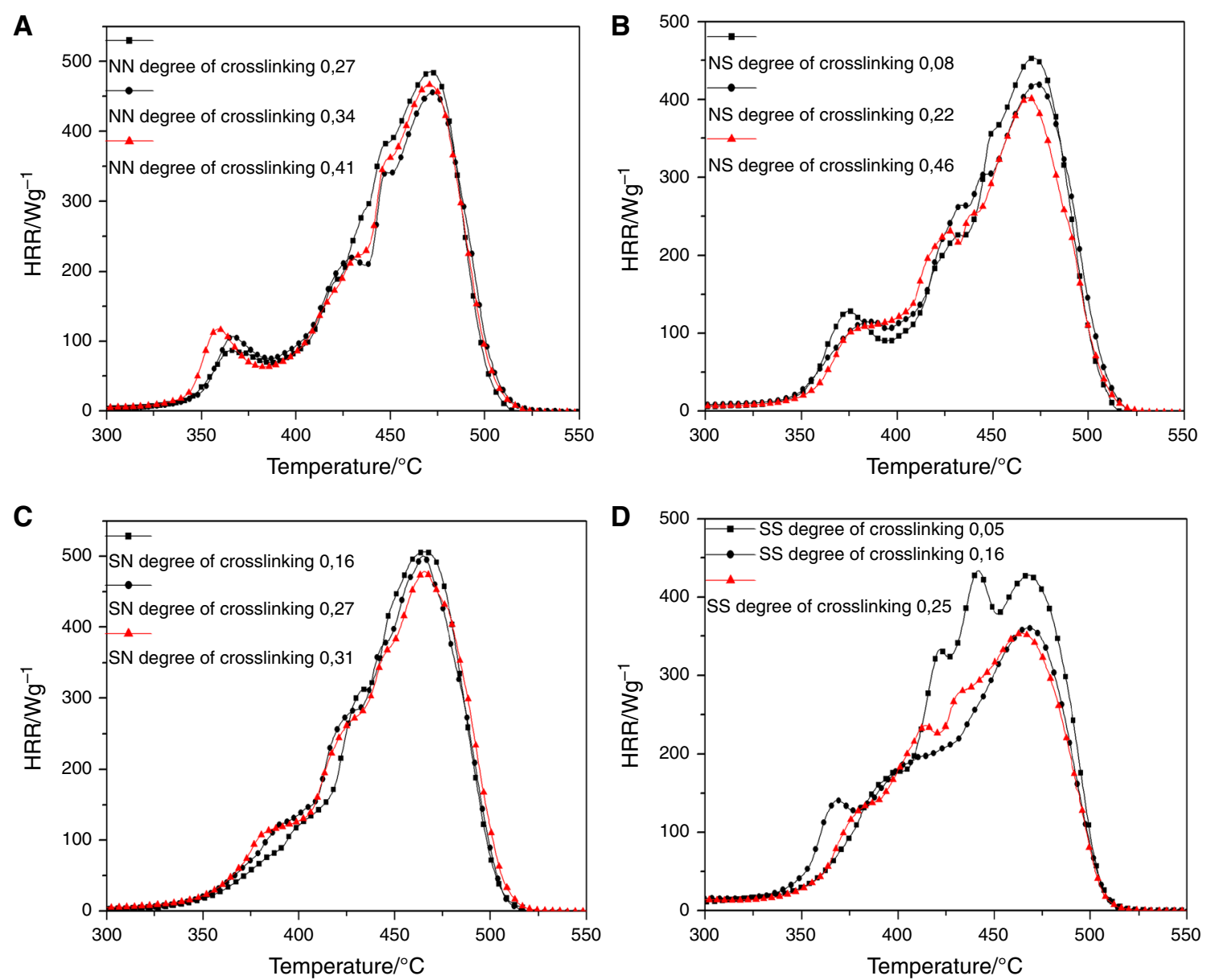

Fig. 13 The relation of HRR parameter from degree of cross-linking. a, b NBR vulcanizates. c, d SBR vulcanizates

regardless of the chemical structure of the elastomer contained in them, a small peak is shown in HRR curves at $T \approx 270{ }^{\circ} \mathrm{C}$ (Figs. 11, 12). From our previous studies it follows that under conditions of thermal analysis, iodoform is violently decomposed at a temperature of $160{ }^{\circ} \mathrm{C}[23]$, while in the polymer matrix, its decomposition temperature is $T \approx 270{ }^{\circ} \mathrm{C}$. So, one may assume that the heat realizing during the combustion of NI and SI within this temperature range is due to the secondary exothermic reactions induced by the decomposition of iodoform in the matrix of NBR or SBR.

It should be clearly underlined that in all the HRR curves of the butadiene-acrylonitrile rubber conventionally cross-linked, one can clearly observe so-called "saddle" indicating the formation of a carbonized layer on the surface of burn material, constituting a barrier against mass and energy transport.

The effect of cross-link density on the value of $H_{R R} R_{\text {MAX }}$ is observed in the case of sulfur vulcanizates, especially of SBR. The degradation of sulfur vulcanizates mainly occurs as a result of breaking weak sulfide bonds, which is not facilitated by the monomer splitting off. The macroradicals, in which a free electron is on the sulfur atom, are mainly stabilized due to cyclization, modification, and secondary cross-linking reactions. A lower quantity of flammable gaseous products is passing then to flame than in the case of peroxide vulcanizates [10].

The decrease in the value of $\mathrm{HRR}_{\mathrm{MAX}}$ as a function of cross-link density of SBR is connected with a considerable increase in its smoke-forming capability in relations to NBR rubber. The high-smoke emission during the combustion of SBR is connected with the presence of aromatic rings in the macromolecules of this elastomer, which during burning initiate the formation of great amounts of thermal decomposition products and carbon black [24]. The presence of sulfide crosswise bonds additionally increases the amount of smoke. The chimney effect connected with the formation of considerable amount of smoke exerts a significant effect on the decrease in the value of HRR $_{\text {MAX }}$ (Fig. 13). 


\section{Conclusions}

The cross-linking of NBR and SBR rubbers with the use of conventional cross-linker system, i.e., sulfur or organic peroxide increases their thermal stability expressed by the value of the destruction activation energy $E_{\mathrm{a}}$, which indicates an increase in the cage effect in the mechanism of macroradical's stabilization.

Both NBR and SBR cross-linked with DCP are characterized by higher values of $E_{\mathrm{a}}$ in comparison with those of the sulfur vulcanizates of these elastomers, which is connected with a higher energy of $\mathrm{C}-\mathrm{C}$ crosswise bonds $\left(268-336 \mathrm{~kJ} \mathrm{~mol}^{-1}\right)$ in relation to crosswise sulfide bonds $\left(139-256 \mathrm{~kJ} \mathrm{~mol}^{-1}\right)$.

In most polymers, including elastomers, the values of the destruction activation energy under air is decisively lower than that under nitrogen, as oxygen facilitates thermo-oxidative processes that cause chemical bonds breaking in macromolecular chains.

The test results obtained show that in the case of crosslinked elastomers, the value of $E_{\mathrm{a}}$ under air is higher than that under inert gas.

Based on the parameter $\mathrm{HRR}_{\mathrm{MAX}}$ determining the maximal heat release rate during combustion, one may conclude that the fire hazards of peroxide and iodoform vulcanizates of NBR are comparable, while the fire hazard of the iodoform vulcanizate of SBR is considerably lower than that of its peroxide vulcanizate.

In the HRR curves of the butadiene-acrylonitrile rubber conventionally cross-linked, one can clearly observe socalled "saddle" indicating the formation of a carbonized layer on the surface of material under combustion constituting a barrier to mass and energy transport.

Open Access This article is distributed under the terms of the Creative Commons Attribution License which permits any use, distribution, and reproduction in any medium, provided the original author(s) and the source are credited.

\section{References}

1. Ozawa TA. New method of analyzing thermogravimetric data. Bull Chem Soc Jpn. 1965;38:1881-6.

2. Flynn JH, Wall LA. A quick, direct method for determination of activation energy from thermogravimetric data. J Polym Sci Lett. 1966;4:323-8.

3. Vyazovkin S, Burnham AK, Criado JM, Perez-Maqueda LA, Popescu C, Sbirrazzuoli N. ICTAC Kinetics Committee recommendations for performing kinetic computations on thermal analysis data. Thermochim Acta. 2011;520:1-19.

4. Flory PJ. Statistical mechanics of swelling of network structures. J Chem Phys. 1950;18:108-11.

5. Guo B, Lei Y, Chen F, Liu X, Du M, Jia D. Styrene-butadiene rubber/halloysite nanotubes nanocomposites modified by methacrylic acid. Appl Surf Sci. 2008;255:2715-22.
6. Rybiński P, Janowska G, Jóźwiak MA, Jóźwiak M. Thermal stability and flammability of butadiene-styrene rubber nanocomposites (SBR). Effect of attapulgite, silica, carbon nanofiber and the synergism of their action on the properties SBR composites. J Therm Anal Calorim. 2013;113:43-52.

7. Rybiński P, Janowska G. Thermal stability and flammability of nanocomposites made of diene rubbers and modified halloysite nanotubes. J Therm Anal Calorim. 2013;113:31-41.

8. Rybiński P, Janowska G. Thermal properties and flammability of nanocomposites based on nitrile rubbers and activated halloysite nanotubes and carbon nanofibers. Thermochim Acta. 2012;549: $6-12$.

9. Janowska G, Ślusarski L. Effect of the network structure on the flammability of cis-1.4-polyisoprene vulcanizates. J Therm Anal. 1985;30:1105-13.

10. Janowska G. Thermal stability and elastomers flammability. Łódź: Zeszyty naukowe Politechniki Łódzkiej; 1998.

11. Chrissafis K, Paraskevopoulos KM, Stavrev SY, Decoslis A, Vassiliou A, Bikiaris DN. Characterization and thermal degradation mechanism of isotactic polypropylene/carbon black nanocomposites. Thermochim Acta. 2007;465:6-17.

12. Peterson JD, Vyazovkin S, Wight ChA. Kinetics of the thermal and thermo-oxidative degradation of polystyrene, polyethylene and polypropylene. Macromol Chem Phys. 2001;202:775-84.

13. Scott G. Initiation processes in polymer degradation. Polym Degrad Stab. 1995;48:315-24.

14. Rybiński P, Janowska G, Plis A. Thermal properties and flammability of ethylene-vinyl acetate rubbers (EVM) and their crosslinked blends with nitrile rubber (NBR). Thermochim Acta. 2013;568:104-14.

15. Abadir EF. Mechanism and kinetics of the non-isothermal degradation of ethylenopropylene diene monomer (EPDM). J Therm Anal Calorim. 2009;. doi:10.1007/s10973-009-0308-9.

16. Gamlin CD, Dutta NK, Choudhury NR. Mechanism and kinetics of isothermal thermodegradation of ethylene-propylene-diene (EPDM) elastomers. Polym Degrad Stab. 2003;80:525-31.

17. Gamlin C, Markovic G, Dutta NK, Choudhury NR, Matisons JG. Structural effects on the decomposition kinetics of EPDM elastomers by high-resolution TGA and modulated TGA. J Therm Anal Calorim. 2000;59:319-36.

18. Marinović-Cincović M, Janković B, Jovanović V, SamarźijaJovanović S, Marković G. The kinetic and thermodynamic analyses of non-isothermal degradation process of acrylonitrilebutadiene and ethylene-propylene-diene rubbers. Compos B. 2013;45:321-32.

19. Janowska G, Ślusarski L. Thermal properties of cis-1.4poly(butadiene). J Therm Anal Calorim. 2001;65:205-12.

20. Amraee A. The effect of heat history on thermal degradation of elastomers containing butadiene units. J Appl Polym Sci. 2009; 113:3896-900.

21. Janowska G, Kucharska A. The influence of the method of butadiene rubbers cross-linking on their thermal properties. J Therm Anal Calorim. 2009;96:561-5.

22. Rybiński P, Janowska G, Antkowicz W, Krauze S. Thermal stability and flammability of butadiene-acrylonitrile rubber crosslinked with iodoform. J Therm Anal Calorim. 2005;81:9-13.

23. Rybiński P, Janowska G. Influence of network structure of nitrile rubbers on their thermal properties. Polimery. 2009;54:275-82.

24. Rybiński P, Janowska G, Kucharska-Jastrząbek A, Pająk A, Wójcik I, Wesołek D, Bujnowicz K. Flammability of vulcanizates of diene rubbers. J Therm Anal Calorim. 2012;107:1219-24.

25. Chen KS, Yeh RZ. Kinetics of thermal decomposition of styrenebutadiene rubber at low heating rates in nitrogen and oxygen. Combust Flame. 1997;108:408-18. 